\title{
BMJ Open Severity of coeliac disease and clinical management study when using a CYP3A4 metabolised medication: a phase I pharmacokinetic study
}

\author{
Marc L Chretien, ${ }^{1}$ David G Bailey (D) , ${ }^{1,2}$ Linda Asher, ${ }^{1}$ Jeremy Parfitt, ${ }^{3}$ \\ David Driman, ${ }^{3}$ Jamie Gregor, ${ }^{1}$ George K Dresser ${ }^{1,2}$
}

To cite: Chretien ML, Bailey DG, Asher L, et al. Severity of coeliac disease and clinical management study when using a CYP3A4 metabolised medication: a phase I pharmacokinetic study. BMJ Open 2020;10:e034086. doi:10.1136/ bmjopen-2019-034086

- Prepublication history and additional material for this paper are available online. To view these files, please visit the journal online (http://dx.doi. org/10.1136/bmjopen-2019034086).

Received 04 September 2019 Revised 15 January 2020 Accepted 07 February 2020

Check for updates

(c) Author(s) (or their employer(s)) 2020. Re-use permitted under CC BY-NC. No commercial re-use. See rights and permissions. Published by BMJ.

${ }^{1}$ Medicine, London Health Sciences Centre, London, Ontario, Canada

${ }^{2}$ Lawson Health Research Institute, London, Ontario, Canada

${ }^{3}$ Pathology and Laboratory Medicine, London Health Sciences Centre, London, Ontario, Canada

Correspondence to

Dr David G Bailey;

david.bailey@lhsc.on.ca

\section{ABSTRACT}

Objective Severity of coeliac disease depends in part on the extent of small intestinal mucosa injury. Patients with the most abnormal pathology have loss of duodenal villi CYP3A4, a drug-metabolising enzyme that inactivates many drugs. These patients are hypothesised to have greater systemic concentrations of felodipine, a drug which normally has low oral bioavailability secondary to intestinal CYP3A4-mediated metabolism. It serves as a representative for a class containing many medications.

Design A phase I, open-label, single-dose,

pharmacokinetic study.

Setting London, Ontario, Canada.

Participants Patients with coeliac disease $(n=47)$ with positive serology and healthy individuals $(n=68)$.

Main outcome measures Patients with coeliac disease-upper gastrointestinal endoscopy and oral felodipine pharmacokinetics study within a 3-week period. Healthy individuals—oral felodipine pharmacokinetics study with water and grapefruit juice.

Results Coeliac stratification categories: Group A ( $n=15$, normal), $B+C$ ( $n=16$, intraepithelial lymphocytosis with/ without mild villous blunting) and $D$ ( $n=16$, moderate/ severe villous blunting). Groups $A, B+C$ and $D$ had linear trends of increasing felodipine $\mathrm{AUC}_{0-8}$; mean $\pm \mathrm{SEM}$, $14.4 \pm 2.1,17.6 \pm 2.8,25.7 \pm 5.0 ; p<0.05)$ and $C \max$ $(3.5 \pm 0.5,4.0 \pm 0.6,6.4 \pm 1.1 ; p<0.02)$, respectively. Healthy subjects receiving water had lower felodipine $\mathrm{AUC}_{0-8}$ $(11.9 \pm 0.9$ vs $26.9 \pm 0.9, p=0.0001)$ and $C \max (2.9 \pm 0.2$ vs $7.7 \pm 0.2, p=0.0001$ ) relative to those receiving grapefruit juice.

Conclusions Increased felodipine concentrations in patients with coeliac disease were most probably secondary to decreased small intestinal CYP3A4 expression. Patients with severe coeliac disease and healthy individuals with grapefruit juice had equivalently enhanced effect. Thus, patients with severe coeliac disease would probably experience similarly altered drug response, including overdose toxicity, from many important medications known to be metabolised by CYP3A4. Patients with coeliac disease with severe disease should be considered for other clinical drug management, particularly when there is the potential for serious drug toxicity.
Strengths and limitations of this study

- Only unequivocally diagnosed patients with coeliac disease who differed in severity of disease were included.

- The maximum time interval of 3 weeks between gastrointestinal biopsy and pharmacokinetic drug testing provided an accurate measure of their relationship.

- Felodipine is a relatively safe representative of a class containing many orally administered drugs that undergo intestinal metabolism by CYP3A4.

- Healthy controls (negative, positive) underwent comparable testing to patients with coeliac disease and were of sufficient number to define felodipine population pharmacokinetics well.

- A limitation was the incorporation of healthy subjects from several of our previously published studies as controls.

\section{INTRODUCTION}

Coeliac disease affects an estimated $1 \%$ of the population worldwide with recent reports suggesting that it may be on the rise. ${ }^{1-3}$ It is a T-cell-mediated type IV hypersensitivity reaction that occurs in genetically susceptible individuals following consumption of glutencontaining foods like wheat, rye or barley.

There is a paucity of information about drug interactions in coeliac disease and thus this issue is poorly understood. ${ }^{1-3}$ The enzyme, CYP3A4, is a key member of the cytochrome P450 family as it metabolises about $50 \%$ of all drugs. ${ }^{4}$ Thus, it plays an important role in many drug interactions that result from inhibition or induction of CYP3A4 that might thereby change systemic drug concentration and associated clinical response. The location of CYP3A4 in duodenal villous epithelial and hepatic parenchymal cells enables biotransformation of orally administered medications before they gain access to the central circulation, a process known as presystemic 
(first pass) drug metabolism. ${ }^{45}$ Approved drug regimens routinely correct for this effect by increasing the oral dose.

Patients with severe coeliac disease had marked blunting of duodenal villi and low expression of CYP3A subfamily proteins. ${ }^{6}$ Moreover, a gluten-free diet that returned intestinal histology to normal resulted in much higher expression of these proteins. ${ }^{6}$ Grapefruit juice can also abolish the content of small intestinal CYP3A4. ${ }^{57}$ This effect is the basis by which this fruit can augment the oral bioavailability of a wide range of drugs. ${ }^{5}$ Clinically, the primary concern is the potential to cause excessive drug concentration and greater risk of overdose toxicity. This investigation is the first to our knowledge to test the hypothesis that the severity of coeliac disease affects the systemic concentration of an orally administered archetypal drug that undergoes substantial presystemic metabolism by CYP3A4.

\section{METHODS}

\section{Patients with coeliac disease}

\section{Study population}

Patients were initially contacted by their gastroenterologist about participation in this research study during a routine clinical appointment. Reasons for exclusion were significant illness within 2 weeks before either the endoscopy or drug pharmacokinetic testing, history of drug or alcohol abuse, pregnancy, breast feeding or using an unreliable birth control method. Those expressing interest received a copy of the approved human ethics letter of information which noted that their decision would not affect their subsequent healthcare or physician-patient relationship. They were asked to attend a regularly scheduled meeting of the Celiac Society of London, Ontario. The principal investigator (George $\mathrm{K}$ Dresser, $\mathrm{MD} \mathrm{PhD}$ ) and research coordinator (Linda Asher, RN) introduced the project to those about to have an endoscopy as part of their standard of care. These patient advisers discussed aspects of the drug pharmacokinetics research testing including the inconvenience, benefits and risks. This group meeting format enabled open discussion among the patients and was likely a significant aspect determining their participation. Importantly, it provided a process for them to make a well-informed decision.

All patients provided written informed consent for this study which had been approved by the University of Western Ontario Research Ethics Board for Health Sciences Research Involving Human Subjects. A total of 72 patients with coeliac disease expressed interest and met entry criteria, 50 of them completed the felodipine study with no withdrawals during testing and 47 (10 males, 37 females, age range: $18-79$ years) completed both aspects of this investigation as result of 3 patients withdrawing before their endoscopy.

\section{Experimental protocol}

Patients completed the felodipine pharmacokinetic study within 3 weeks of their endoscopy. They avoided consumption of any substance(s) which could have an impact on the bioavailability of felodipine, including grapefruit, Seville orange (marmalades), lime, pomelo, tobacco, alcoholic drinks, medications (prescription and over-the-counter) and natural health products for at least 48 hours before and during this study. All medications taken by the patients with coeliac disease were documented before entry into the study. None were receiving a medication that was either an inhibitor or inducer of CYP3A4 and had an elimination half-life of sufficient duration to have a relevant clinical effect on intestinal CYP3A4 after a 48 hours interval. Testing was preceded by a 10 hours overnight fast. Women of childbearing potential had a urine test to confirm that they were not pregnant just before receiving a felodipine $10 \mathrm{mg}$ extended-release tablet (Plendil; Astra Pharma Inc, Ontario, Canada) with $300 \mathrm{~mL}$ water. Plasma samples were obtained at specified times $(0,0.5,1.0,1.5,2.0,2.5,3.0,4.0,5.0,6.0,7.0,8.0$ hours) relative to dosing for quantitation of felodipine and dehydrofelodipine metabolite concentrations. Blood pressure and heart rate were monitored regularly during the study day for safety reasons. A gluten-free standardised lunch was provided 4 hours after drug dosing (noon).

\section{Healthy subjects}

Study population

Subjects were from six of our peer-reviewed felodipinegrapefruit juice interaction study publications. ${ }^{8-13}$ They had normal findings on physical examination and routine laboratory testing that included hematologic and serum chemistry studies. Female subjects were not pregnant or breastfeeding and were using an effective means for contraception. They provided written informed consent for the original investigation that had been approved by the University of Western Ontario Research Ethics Board for Health Sciences Research Involving Human Subjects. The study population consisted of 68 individuals (54 males, 14 females, age range: $18-83$ years).

\section{Experimental protocol}

Subjects avoided ingestion of the same substances outlined above for the patients with coeliac disease for at least 48 hours before and during each of the study days. They also had a 10 hours overnight fast before testing. All studies had a randomised crossover design with felodipine 10 mg extended-release tablet (Plendil; Astra Pharma Inc) taken with either $250 \mathrm{~mL}$ or $300 \mathrm{~mL}$ of water or grapefruit juice. However, felodipine $5 \mathrm{mg}$ extended-release tablet was used in the seniors' study for safety reasons. ${ }^{10}$ Felodipine has linear dose-concentration relationships. ${ }^{14}$ Thus, data on plasma concentrations of felodipine in this investigation were doubled to correct for this dose inconsistency. Plasma samples were obtained at the same specified times as those for the coeliac study. A standardised lunch was also provided 4 hours after drug dosing (noon) that consisted of a sandwich, ginger ale and ice cream sandwich. The interval between study days was 1 week. 
Assay of plasma felodipine and dehydrofelodipine concentrations

Plasma samples were analysed by a method involving solvent extraction and capillary column gas chromagraphy. ${ }^{15}$ Plasma $(500 \mu \mathrm{L})$ was extracted with toluene $(500 \mu \mathrm{L})$ containing the internal standard (H165/04; AB Haessle, Gothenburg, Sweden) by gentle oscillation of the mixture overnight followed by centrifugation. The toluene phase $(1 \mu \mathrm{L})$ had splitless injection into a dualtapered deactivated glass insert (Hewlett Packard Canada Ltd, Toronto, Ontario, Canada) in a Hewlett Packard 5890 Series II Gas Chromatograph (Hewlett Packard Canada Ltd) equipped with a ${ }^{63} \mathrm{Ni}$ electron capture detector and a $25 \mathrm{~m} \times 0.32 \mathrm{~mm}$ inner diameter fused silica capillary column coated with a stationary phase of methyl silicone, $0.52 \mu \mathrm{m}$ (HP-1; Hewlett Packard Canada Ltd). After a purge time of $1 \mathrm{~min}$, the initial oven temperature of $90^{\circ} \mathrm{C}$ was increased at $30^{\circ} \mathrm{C} / \mathrm{min}$ to $180^{\circ} \mathrm{C}$. This was then increased at $5^{\circ} \mathrm{C} / \mathrm{min}$ to $260^{\circ} \mathrm{C}$ that was held for $3 \mathrm{~min}$. Next, the temperature was increased at $30^{\circ} \mathrm{C} /$ min to a final temperature of $280^{\circ} \mathrm{C}$ that was held for 5 $\min$. The injector port and detector temperatures were maintained at $260^{\circ} \mathrm{C}$ and $300^{\circ} \mathrm{C}$, respectively. The carrier gas was ultrapure helium (column inlet pressure of 100 $\mathrm{kPa})$, and the make-up gas was ultrapure nitrogen $(60$ $\mathrm{mL} / \mathrm{min}$ ). The retention times of felodipine, dehydrofelodipine and internal standard were 20.1, 14.5 and 21.7 min, respectively. The coefficients of variation for plasma felodipine and dehydrofelodipine concentrations were $4.7 \%$ and $2.9 \%$ at $1.0 \mathrm{ng} / \mathrm{mL}(\mathrm{n}=5)$. The limit of detection was $0.25 \mathrm{ng} / \mathrm{mL}$ for both.

\section{Pathological analysis}

All patients had at least one biopsy sample from each of the gastric antrum, the second part of the duodenum ipsilateral to the ampulla of Vater and contralateral to the ampulla of Vater. Where pathological abnormalities were visible macroscopically, additional biopsies were taken. Formalin-fixed, paraffin-embedded tissue was used to prepare H\&E-stained slides using standard techniques. Biopsies were reviewed histologically by two gastrointestinal pathologists (JP, DD) according to a previously reported modified method. ${ }^{16}$ Briefly, samples were scored independently while blinded to clinical and pharmacokinetic data. Findings were then reviewed for any discrepancy between the pathologists in order to reach consensus. A modified Marsh-Oberhuber (M-O) classification: $0=$ normal; $1=$ increased intraepithelial lymphocytes (IELs) only; 2=increased IELs with crypt hyperplasia; and $3 \mathrm{a}-\mathrm{c}=$ increased IELs with mild (3a), marked (3b) or complete $(3 \mathrm{c})$ villous atrophy was used. Two groups were combined since separating crypt hyperplasia from villous blunting was problematic as they could not be reliably distinguished from each other. The end result was: Group $\mathrm{A}=$ normal (M-O score 0 ); Group $\mathrm{B}=$ increased IELs only (M-O score 1); Group C=increased IELs+mild architectural abnormality (M-O scores 2 and 3a); Group $\mathrm{D}=$ increased IELs+moderate to severe architectural
Table 1 Demographic profile of patients with coeliac disease

\begin{tabular}{llcl}
\hline & Group A & Group B+C & Group D \\
\hline Males & 4 & 3 & 3 \\
Females & 11 & 13 & 13 \\
Age & $50(18-71)$ & $54(24-77)$ & $45(21-79)$ \\
tTG-lgA & 1.5 & 4.2 & 42.4 \\
\hline
\end{tabular}

Age (years) expressed as mean (range). tTG-IgA is serum tissue transglutaminase antibody concentration expressed as the arithmetic mean of the log analysed data.

abnormality (M-O scores $3 \mathrm{~b}$ and $3 \mathrm{c}$ ). Moreover, Groups $\mathrm{B}$ and $\mathrm{C}$ were combined because of small sample size in the latter (Group $\mathrm{C}, \mathrm{n}=3$ ). The demographic data are shown in table 1. A positive serum tTG-IgA along with the accompanying pathology results confirmed the diagnosis of coeliac disease in all tested individuals. ${ }^{1-3}$

\section{Pharmacokinetic analyses}

Plasma felodipine and dehydrofelodipine concentrations were measured using the Microsoft program Excel 2016 and analysed by the non-compartmental method. The author (DGB) who calculated the pharmacokinetic results was blinded to the histological reports. The terminal elimination rate constant $\left(\mathrm{k}_{\mathrm{e}}\right)$ was determined by log-linear regression (correlation coefficient of $r>0.95$ for the last three drug concentrations). The apparent elimination half-life $\left(\mathrm{t}^{1 / 2}\right)$ was calculated as $0.693 / \mathrm{k}_{\mathrm{e}}$. Area under plasma drug concentration-time profile from 0 to 8 hours $\left(\mathrm{AUC}_{0-8}\right)$ used the linear trapezoidal method. The AUC from 0 to infinity $\left(\mathrm{AUC}_{0-\infty}\right)$ was $\mathrm{AUC}_{0-8}$ plus $\mathrm{AUC}_{8-\infty}$ with the later calculated by dividing the final plasma drug concentration by $\mathrm{k}_{\mathrm{e}}$. Peak plasma drug concentration (Cmax) and the time to reach Cmax (tmax) were obtained directly from the experimental data.

\section{Statistical analyses}

The initial comparisons of felodipine data were among the five treatment groups by means of a one-way analysis of variance. For those analyses with $\mathrm{p}<0.05$, post-test for linear trend (Groups A, B+C, D) and Bonferroni test for multiple comparisons between selected pairs of treatments (healthy subjects with water vs grapefruit juice, healthy subjects with water vs Group A and healthy subjects with grapefruit juice vs Group D) were conducted using the statistical package in Prism V.3.00. Results are presented as the mean \pm SEM

\section{Patient and public involvement statement}

Patients and public were not involved in the design, conduct or reporting of this study. Once published in a peer-reviewed medical journal, the intention was to invite all participants to a meeting of the Celiac Society of London Ontario to thank them for their important contribution, to disseminate findings of this study and 
to show how drug therapy for them and others with this condition could be improved.

\section{RESULTS}

Plasma concentration-time profiles for felodipine are shown in figure 1. Patients in Groups $\mathrm{A}, \mathrm{B}+\mathrm{C}$ and $\mathrm{D}$ had statistically significant $(p<0.05)$ linear trends for increasing felodipine and dehydrofelodipine AUCs and Cmax (table 2).

Groups $\mathrm{A}$ and $\mathrm{D}$ had felodipine, dehydrofelodipine and ratio pharmacokinetic parameters that were comparable to those for healthy subject controls with water and grapefruit juice, respectively.

Healthy subjects had corresponding felodipine $\mathrm{AUC}_{0-8}$, $\mathrm{AUC}_{0-\infty}$ and Cmax with grapefruit juice (positive control) that were $280 \% \pm 25 \%(\mathrm{p}=0.0001), 347 \% \pm 58 \%(\mathrm{p}=0.0001)$ and $335 \% \pm 34 \%(\mathrm{p}=0.0001)$ of those with water (negative control).

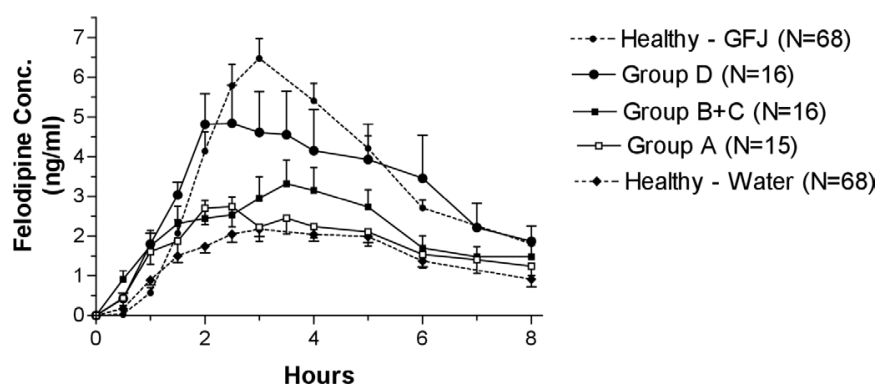

Figure 1 Plasma concentration-time profiles for felodipine for patients with coeliac disease in groups $A, B+C$ and $D$ and healthy controls with grapefruit juice or water. The number of subjects in each group are indicated in parentheses. Data are reported as mean \pm SEM.

\section{DISCUSSION}

Group D patients had the most severe gastrointestinal manifestations of coeliac disease and highest systemic felodipine concentrations being essentially twice those

\begin{tabular}{|c|c|c|c|c|c|}
\hline & $\begin{array}{l}\text { Healthy controls } \\
\text { Water (68) }\end{array}$ & $\begin{array}{l}\text { Patients with } \\
\text { coeliac disease } \\
\text { Group A (15) }\end{array}$ & $\begin{array}{l}\text { Patients with } \\
\text { coeliac disease } \\
\text { Group B+C (16) }\end{array}$ & $\begin{array}{l}\text { Patients with } \\
\text { coeliac disease } \\
\text { Group D (16) }\end{array}$ & $\begin{array}{l}\text { Healthy controls } \\
\text { Grapefruit (68) }\end{array}$ \\
\hline \multicolumn{6}{|l|}{ Felodipine } \\
\hline $\begin{array}{l}\mathrm{AUC}_{0-8} \\
\text { (ng.h/mL) }\end{array}$ & $11.9 \pm 0.9$ & $14.4 \pm 2.1$ & $17.2 \pm 2.8$ & $25.7 \pm 5.0^{*}$ & $26.8 \pm 0.9 \dagger$ \\
\hline $\begin{array}{l}\mathrm{AUC}_{0-\infty} \\
\text { (ng.h/mL) }\end{array}$ & $16.3 \pm 1.4$ & $20.5 \pm 4.5$ & $27.9 \pm 4.5$ & $36.9 \pm 5.6^{*}$ & $36.8 \pm 3.5 \dagger$ \\
\hline $\begin{array}{l}\text { Cmax } \\
(\mathrm{ng} / \mathrm{mL})\end{array}$ & $2.9 \pm 0.2$ & $3.5 \pm 0.5$ & $4.0 \pm 0.6$ & $6.4 \pm 1.1 \ddagger$ & $7.7 \pm 0.2 \dagger$ \\
\hline $\begin{array}{l}\text { tmax } \\
\text { (hours) }\end{array}$ & $3.4 \pm 0.2$ & $3.3 \pm 0.4$ & $3.2 \pm 0.3$ & $3.4 \pm 0.4$ & $3.0 \pm 0.1$ \\
\hline $\begin{array}{l}t^{1} 1 / 2 \\
\text { (hours) }\end{array}$ & $4.5 \pm 0.5$ & $2.6 \pm 0.7$ & $3.6 \pm 0.7$ & $4.5 \pm 1.0$ & $4.7 \pm 0.8$ \\
\hline \multicolumn{6}{|c|}{ Dehydrofelodipine } \\
\hline $\begin{array}{l}\mathrm{AUC}_{0-8} \\
\text { (ng.h/mL) }\end{array}$ & $19.9 \pm 1.3$ & $17.4 \pm 2.1$ & $25.9 \pm 3.9$ & $28.0 \pm 3.8^{*}$ & $27.8 \pm 1.6 \dagger$ \\
\hline $\begin{array}{l}\mathrm{AUC}_{0-\infty} \\
\text { (ng.h/mL) }\end{array}$ & $25.0 \pm 1.7$ & $21.3 \pm 2.5$ & $33.0 \pm 6.0$ & $34.2 \pm 4.1$ & $39.4 \pm 3.1 \dagger$ \\
\hline $\begin{array}{l}\text { Cmax } \\
(\mathrm{ng} / \mathrm{mL})\end{array}$ & $5.4 \pm 0.3$ & $4.4 \pm 0.5$ & $6.5 \pm 0.8$ & $7.4 \pm 1.2 \ddagger$ & $8.4 \pm 0.5 \dagger$ \\
\hline $\begin{array}{l}\text { tmax } \\
\text { (hours) }\end{array}$ & $2.9 \pm 0.1$ & $2.5 \pm 0.3$ & $2.8 \pm 0.3$ & $2.9 \pm 0.3$ & $3.0 \pm 0.1$ \\
\hline $\begin{array}{l}t^{1} 1 / 2 \\
\text { (hours) }\end{array}$ & $3.9 \pm 0.5$ & $2.2 \pm 0.3$ & $2.7 \pm 0.4$ & $5.6 \pm 1.3 \ddagger$ & $4.8 \pm 0.7$ \\
\hline \multicolumn{6}{|c|}{ Dehydrofelodipine/felodipine ratio } \\
\hline $\mathrm{AUC}_{0-8}$ & $2.0 \pm 0.1$ & $1.8 \pm 0.5$ & $1.8 \pm 0.3$ & $1.5 \pm 0.2$ & $1.3 \pm 0.1 \dagger$ \\
\hline
\end{tabular}

Data are presented as mean \pm SEM.

Healthy controls - water versus grapefruit.

${ }^{*} \mathrm{p}<0.05$.

$\dagger p=0.0001$ Healthy controls - water versus grapefruit.

$\neq \mathrm{p}<0.02$.

$\mathrm{AUC}_{0-\infty}$, area under concentration time curve from 0 to infinity; $\mathrm{AUC}_{0-8}$, area under concentration time curve from 0 to 8 hours; $\mathrm{Cmax}$, peak drug concentration; $t_{1 / 2}$, apparent elimination half-life. 
compared with Groups A and B+C. Although coeliac disease is thought to have enhanced intestinal permeability from degradation of the tight junctions of intestinal epithelial cells, this does not likely explain the differing felodipine pharmacokinetics among these groups. ${ }^{1-3}$ This is because a mass balance human investigation with radiolabelled felodipine has shown that all the radioactivity (parent drug plus metabolites) was completely orally absorbed even in healthy subjects with intact tight junctions. ${ }^{17}$ On the other hand, the absolute oral bioavailability of felodipine alone was just $16 \%$ as result of both intestinal and hepatic presystemic drug metabolism. ${ }^{17}$ Therefore, it is more conceivable that variances in pharmacokinetics among the three coeliac groups were due to differences in presystemic felodipine metabolism by CYP3A4. ${ }^{9}$ Felodipine has substantial intestinal metabolism based on results showing selective inhibition by grapefruit and associated enhanced systemic drug concentration. ${ }^{7}$ Also, the similarities of felodipine pharmacokinetics between Group D patients with coeliac disease and healthy subjects receiving grapefruit support the mutual mechanism of diminished small intestinal CYP3A4 expression and resulting activity. ${ }^{67}$

Felodipine has the single primary metabolite dehydrofelodipine. ${ }^{9}$ The metabolism of both felodipine and dehydrofelodipine is mediated by CYP3A $4 .{ }^{9}$ Increased felodipine and dehydrofelodipine AUC and Cmax, decreased dehydrofelodipine/felodipine AUC ratio and no alteration in tmax nor $t^{1 / 2}$ are consistent with lower presystemic CYP3A4 activity. ${ }^{9}$ The similar changes in felodipine, dehydrofelodipine and ratio pharmacokinetics for patients with severe coeliac disease (Group D) and for healthy subjects with grapefruit (positive control) provide additional support consistent with a common cause of lower small intestinal CYP3A4 expression that is known to occur in these two circumstances. ${ }^{67}$

The mainstay of treatment for coeliac disease is a lifelong gluten-free diet. ${ }^{1-3}$ Yet, it is highly likely that patients with coeliac disease will require drug therapy for either coeliac associated conditions or comorbid illness. ${ }^{3} 18$ Given the similarity in magnitude of response and cause, we propose that in patients with severe coeliac disease drugs would also have augmented oral bioavailability with the same drugs interacting with grapefruit juice. They possess the essential criteria of: (1) oral route of administration, (2) very low $(<10 \%)$ to intermediate $(30 \%-70 \%)$ intrinsic oral bioavailability and (3) extensive metabolism by CYP3A $4 .{ }^{5}$ These medications comprise anticancer, anti-infective, antilipemic, cardiovascular, central nervous system, gastrointestinal, immunosuppressant and urinary tract agents. ${ }^{5}$ Overall, more than 100 drugs are currently cited with 68 having the potential for serious adverse events (online supplementary file 1 . Reproduced with permission from the Compendium of Pharmaceuticals and Specialties. Canadian Pharmacists Association copyright 2020, Ottawa, Canada. Available by subscription at htts://myrxtx.ca). ${ }^{19}$ Torsade de pointes, which has a $10 \%-20 \%$ risk of sudden death, is possible for 30 of them. ${ }^{19}{ }^{20}$ Other toxicities are rhabdomyolysis, myelotoxicity, respiratory depression, gastrointestinal bleeding and nephrotoxicity. ${ }^{519}$ A list of the more commonly prescribed drugs and associated toxicities is found in table 3.

Patients with coeliac disease in Group $\mathrm{B}+\mathrm{C}$ had a composite of histological and serological pathology that supported a milder form of coeliac disease ${ }^{1-3}$ The intraepithelial lymphocytosis that was present implied inflammation and elevated cytokines which might downregulate the expression of drug metabolising enzymes. ${ }^{21}{ }^{22}$ Indeed, cytokine immunotherapy with high-dose interleukin-2 (IL-2) clinically reduced the liver protein content and erythromycin N-demethylation activity of CYP3A4 in patients with hepatic cancer. ${ }^{23}$ Also, the human IL-6 antibody, tocilizumab, decreased plasma C-reactive protein and enhanced first pass CYP3A4 activity as determined by lower oral simvastatin bioavailability in rheumatoid arthritis. ${ }^{24}$ However, Group $\mathrm{B}+\mathrm{C}$ mean felodipine $\mathrm{AUC}_{0-8}$ and Cmax were $119 \%$ and $116 \%$ of those in Group A, respectively, suggesting lack of meaningful impairment of intestinal CYP3A4-mediated drug metabolism. Thus, Groups $\mathrm{A}$ and $\mathrm{B}+\mathrm{C}$ patients might be considered for the standard prescribed drug dosage regimen. However, caution may still be suitable with careful follow-up at the initiation of treatment with a drug that meets the criteria mentioned above for an interaction with grapefruit and has the possibility of serious overdose toxicity.

Reports of coeliac disease-related adverse drug reactions are infrequent. Yet, seven to eight patients with this disease are estimated to go undetected for every patient positively diagnosed.$^{25}$ Despite the popular attention given to gluten sensitivity, patients with active coeliac continue to wait months from first contact until a firm diagnosis is established. ${ }^{3}$ This study also shows that the risk may reside primarily with the more severe forms of this condition. Perhaps, these are confounders in the diagnosis of coeliac disease that create uncertainties about causality of observed adverse drug events. Thus, we postulate that overdose drug toxicity may be more common in active coeliac disease but has yet to be identified due in part to lack of awareness of the possibility.

We examined patients at a single time point during their illness. Therefore, our data did not allow for insight into the change in felodipine pharmacokinetics that might occur with an improvement or a deterioration in their disease status. For example, successful treatment with a gluten-free diet was mirrored with the return of intestinal CYP3A protein expression. ${ }^{6}$ Our patients with normal intestinal mucosal histology had felodipine pharmacokinetics similar to those for healthy subjects with water (negative control). Thus, it is plausible that a lower dose may provide a therapeutic effect during serious active disease, while an increased dose may be required to offset the loss of drug therapeutic effect during enteric histologic recovery to a milder form of the disease, a period that would take months for the average patient.

One possible criticism of this investigation might be the inclusion of previously tested healthy subjects as controls. 
Table 3 Commonly prescribed grapefruit-affected drugs and possible adverse events*

\begin{tabular}{|c|c|}
\hline Amiodarone & Torsades de pointes \\
\hline Apixaban & Gastrointestinal bleeding \\
\hline Atorvastatin & Myopathy, rhabdomyolysis \\
\hline Budesonide (oral) & $\begin{array}{l}\text { Hyperglycaemia, Cushingoid } \\
\text { features }\end{array}$ \\
\hline Buprenorphine (buccal) & $\begin{array}{l}\text { Torsades de pointes, respiratory } \\
\text { depression }\end{array}$ \\
\hline Buspirone & $\begin{array}{l}\text { Sedation, psychomotor } \\
\text { impairment }\end{array}$ \\
\hline Clopidogrel & Lack of efficacy \\
\hline Cyclophosphamide & Lack of efficacy \\
\hline Cyclosporine & $\begin{array}{l}\text { Nephrotoxicity, excessive } \\
\text { immunosuppression }\end{array}$ \\
\hline Dextromethorphan & $\begin{array}{l}\text { Dizziness, somnolence, anxiety, } \\
\text { hallucinations }\end{array}$ \\
\hline Domperidone & Torsades de pointes \\
\hline Dronedarone & Torsades de pointes \\
\hline Felodipine & $\begin{array}{l}\text { Headache, peripheral oedema, } \\
\text { hypotension }\end{array}$ \\
\hline Fentanyl (sublingual) & Sedation, respiratory depression \\
\hline Ketamine (oral) & $\begin{array}{l}\text { Hallucinations, loss of } \\
\text { coordination and motor skills }\end{array}$ \\
\hline Loperamide & $\begin{array}{l}\text { Drowsiness, respiratory } \\
\text { depression }\end{array}$ \\
\hline Lovastatin & Myopathy, rhabdomyolysis \\
\hline Lurasidone & Torsades de pointes \\
\hline Methadone & Sedation, respiratory depression \\
\hline Methylprednisolone (oral) & $\begin{array}{l}\text { Hyperglycaemia, Cushingoid } \\
\text { features }\end{array}$ \\
\hline Nifedipine & $\begin{array}{l}\text { Headache, peripheral oedema, } \\
\text { hypotension }\end{array}$ \\
\hline Oxycodone & Sedation, respiratory depression \\
\hline Quetiapine & $\begin{array}{l}\text { Dizziness, somnolence, } \\
\text { hypotension }\end{array}$ \\
\hline Rivaroxaban & Gastrointestinal bleeding \\
\hline Silodosin & Dizziness, weakness, syncope \\
\hline Simvastatin & Myopathy, rhabdomyolysis \\
\hline Solifenacin & Torsades de pointes \\
\hline Tacrolimus & $\begin{array}{l}\text { Torsades de pointes, } \\
\text { nephrotoxicity, neurotoxicity }\end{array}$ \\
\hline Tamsulosin & Orthostatic hypotension \\
\hline Ticagrelor & Gastrointestinal bleeding \\
\hline Triazolam & Excessive drowsiness, sedation \\
\hline Verapamil & $\begin{array}{l}\text { Arrhythmias (heart block, } \\
\text { bradycardia), hypotension }\end{array}$ \\
\hline Ziprasidone & $\begin{array}{l}\text { Torsades de pointes, orthostatic } \\
\text { hypotension }\end{array}$ \\
\hline
\end{tabular}

*Adapted from Bailey. ${ }^{19}$
On the other hand, the experimental protocol and study testing environment were essentially identical to those for the patients with coeliac disease. Moreover, this method enabled involvement of a high number of individuals who could define descriptive and comparative statistics better than might have been otherwise possible. Another concern may be the lack of balance in the number of males to females between patients with coeliac disease $(10 / 37)$ and healthy subjects $(54 / 14)$. However, a genderdependent effect on felodipine population pharmacokinetics has not been previously observed. ${ }^{26}$

\section{CONCLUSION}

This study suggests that patients with coeliac disease, particularly those with severe disease, may experience adverse effects from CYP3A4 metabolised medications when given a standard recommended drug dose. This could either be excessive response from overdose or inadequate benefit from insufficient conversion of the prodrug to the active metabolite. Those recovering from a severe disease following successful treatment with a gluten-restricted diet face a new challenge. The previously stabilised dose of drug may need to be enhanced to attain an adequate therapeutic effect. Therefore, careful titration of all CYP3A4 metabolised medications is recommended in all patients with coeliac disease. An alternate and easier approach may be the prescribing of a therapeutically equivalent drug not metabolised by CYP3A $4 .{ }^{519}$ A busy clinician concerned about a drug interaction may use the propensity of such with grapefruit as an indicator of the likelihood of altered effects in patients with active coeliac disease.

Acknowledgements The healthcare providers (George K Dresser MD PhD, Jamie Gregor MD, Linda Asher RN) wish to thank the study patients for their contributions which is hoped to improve the safety and efficacy of a wide range of drugs that might be taken in coeliac disease. The authors wish to thank the attending gastroenterologist Dr Terry Ponich for his role in assisting in patient enrolment and Dr Santiago Vilanova PhD for conducting analysis of plasma samples for felodipine and dehydrofelodipine concentrations.

Collaborators Terry Ponich, Santiago Vilanova.

Contributors MLC helped in drafting and critical revision of the manuscript and statistical analysis. DGB was the guarantor of the study, and helped in study concept and design, analysis and interpretation of data, drafting and critical revision of the manuscript, statistical analysis and obtained funding. LA helped in acquisition and finalising data and administrative, study supervision. JP helped in analysis and interpretation of data and critical revision of the manuscript. DD helped in analysis and interpretation of data and critical revision of the manuscript. JG helped in critical revision of the manuscript and administration. GKD served as a guarantor, and helped in study concept and design, acquisition of data, drafting and critical revision of the manuscript, obtained funding and study supervision.

Funding This study was wholly supported by Canadian Institute of Health Research (Grant \#MOP 77569) and Physicians' Services Incorporated Foundation (Grant \#04-51).

Competing interests None declared.

Patient consent for publication Not required.

Provenance and peer review Not commissioned; externally peer reviewed. Data availability statement No data are available.

Open access This is an open access article distributed in accordance with the Creative Commons Attribution Non Commercial (CC BY-NC 4.0) license, which 
permits others to distribute, remix, adapt, build upon this work non-commercially, and license their derivative works on different terms, provided the original work is properly cited, appropriate credit is given, any changes made indicated, and the use is non-commercial. See: http://creativecommons.org/licenses/by-nc/4.0/.

\section{ORCID iD}

David G Bailey http://orcid.org/0000-0002-9482-2552

\section{REFERENCES}

1 Leonard MM, Sapone A, Catassi C, et al. Celiac disease and Nonceliac gluten sensitivity: a review. JAMA 2017;318:647-56.

2 Lebwohl B, Sanders DS, Green PHR. Coeliac disease.. Lancet 2018;391:70-81.

3 Lindfors K, Ciacci C, Kurppa K, et al. Coeliac disease. Nat Rev Dis Primers 2019;5:1-18.

4 Wilkinson GR. Drug metabolism and variability among patients in drug response. N Engl J Med 2005;352:2211-21.

5 Bailey DG, Dresser G, Arnold JMO. Grapefruit-medication interactions: forbidden fruit or avoidable consequences? CMAJ 2013;185:309-16.

6 Lang CC, Brown RM, Kinirons MT, et al. Decreased intestinal CYP3A in celiac disease: reversal after successful gluten-free diet: a potential source of interindividual variability in first-pass drug metabolism. Clin Pharmacol Ther 1996;59:41-6.

7 Lown KS, Bailey DG, Fontana RJ, et al. Grapefruit juice increases felodipine oral availability in humans by decreasing intestinal CYP3A protein expression. J Clin Invest 1997;99:2545-53.

8 Bailey DG, Bend JR, Arnold JM, et al. Erythromycin-felodipine interaction: magnitude, mechanism, and comparison with grapefruit juice. Clin Pharmacol Ther 1996;60:25-33.

9 Bailey DG, Kreeft JH, Munoz C, et al. Grapefruit juice-felodipine interaction: effect of naringin and 6',7'-dihydroxybergamottin in humans. Clin Pharmacol Ther 1998;64:248-56.

10 Dresser GK, Bailey DG, Carruthers SG. Grapefruit juice-felodipine interaction in the elderly. Clin Pharmacol Ther 2000;68:28-34.

11 Bailey DG, Dresser GK, Kreeft JH, et al. Grapefruit-felodipine interaction: effect of unprocessed fruit and probable active ingredients. Clin Pharmacol Ther 2000;68:468-77.
12 Dresser GK, Wacher V, Wong S, et al. Evaluation of peppermint oil and ascorbyl palmitate as inhibitors of cytochrome P4503A4 activity in vitro and in vivo. Clin Pharmacol Ther 2002;72:247-55.

13 Bailey DG, Dresser GK, Bend JR. Bergamottin, lime juice, and red wine as inhibitors of cytochrome P450 3A4 activity: comparison with grapefruit juice. Clin Pharmacol Ther 2003;73:529-37.

14 Edgar B, Hoffmann KJ, Lundborg P, et al. Absorption, distribution and elimination of felodipine in man. Drugs 1985;29:9-15.

15 Bailey DG, Dresser GK, Urquhart BL, et al. Coffee-antihypertensive drug interaction: a hemodynamic and pharmacokinetic study with felodipine. Am J Hypertens 2016;29:1386.93.

16 Sey MSL, Parfitt J, Gregor J. Prospective study of clinical and histological safety of pure and uncontaminated Canadian oats in the management of celiac disease. JPEN J Parenter Enteral Nutr 2011;35:459-64.

17 Edgar B, Regårdh CG, Johnsson G, et al. Felodipine kinetics in healthy men. Clin Pharmacol Ther 1985;38:205-11.

18 Green PHR, Cellier C. Celiac disease. N Engl J Med 2007;357:1731-43.

19 Bailey DG. Drug administration and grapefruit. In: Compendium of pharmaceuticals and specialties. Ottawa, Ontario, Canada: Canadian Pharmacists Association, 2019: L11-L46.

20 Shah RR. Drug-Induced QT interval prolongation: does ethnicity of the thorough QT study population matter? Br J Clin Pharmacol 2013;75:347-58.

21 Renton KW. Cytochrome P450 regulation and drug biotransformation during inflammation and infection. Curr Drug Metab 2004;5:235-43.

22 Aitken AE, Richardson TA, Morgan ET. Regulation of drugmetabolizing enzymes and transporters in inflammation. Annu Rev Pharmacol Toxicol 2006;46:123-49.

23 Elkahwaji J, Robin MA, Berson A, et al. Decrease in hepatic cytochrome P450 after interleukin-2 immunotherapy. Biochem Pharmacol 1999;57:951-4.

24 Schmitt C, Kuhn B, Zhang X, et al. Disease-drug-drug interaction involving tocilizumab and simvastatin in patients with rheumatoid arthritis. Clin Pharmacol Ther 2011;89:735-40.

25 Mäki M, Kallonen K, Lähdeaho ML, et al. Changing pattern of childhood coeliac disease in Finland. Acta Paediatr Scand 1988;77:408-12

26 Blychert E, Edgar B, Elmfeldt D, et al. A population study of the pharmacokinetics of felodipine. Br J Clin Pharmacol 1991;31:15-24. 